\title{
Hormonal Assay following Administration of Methanolic Leaf Extract of Vernonia Amygdalina on Streptozotocin (STZ) Induced Diabetic Male Wistar Rats
}

\author{
Victor A. Fischer ${ }^{1}$, Christie E. Fischer ${ }^{2}$ \\ ${ }^{1,2}$ Department of Anatomical Sciences, Faculty of Basic Medical Sciences, University of Calabar, Calabar. Nigeria
}

\begin{abstract}
This study analyzed the effect of methanolic leaf extract of Vernonia amygdalina (VA) on male reproductive hormones in streptozotocin (STZ) induced diabetic male Wistar rats. Group A was the normal control that received 0.5ml dimethylsulphoxide (DMSO) only. Group B served as the diabetic control that was induced $40 \mathrm{mg} / \mathrm{kg}$ b.w of STZ intraperitoneally. Group C received 5i.u/kg body weight of insulin. Group D received $400 \mathrm{mg} / \mathrm{kg}$ b.w of VA and Group E served as the $30 \%$ methanolic VA fraction (flavonoid rich fraction) group receiving $75 \mathrm{mg} / \mathrm{kg} \mathrm{b.w}$ of the extract. The animals were sacrificed using chloroform inhalation method after 28 days. Hormonal analysis showed a significant increase in the serum concentration level of testosterone in group $C, D$ and $E$, respectively when compared to group B. Analysis on serum concentration level of LH and FSH showed no significant difference among and within the treated groups when compared to the group $A$ and $B$. This signifies a supplementary role played by insulin, crude extract and $30 \%$ fraction of VA on the anterior pituitary gland to increase testosterone level without a considerable increase in LH and FSH level. Methanolic leaf extract of VA and $30 \%$ methanol VA fraction has effect on male reproductive hormones in diabetic rats and a more potent effect was exhibited by the crude extract of VA. Vernonia amygdalina may help ameliorate reproductive complications caused by diabetes in reproductive males.
\end{abstract}

Keywords: Vernonia amygdalina, testosterone, follicule stimulating hormone, luteinizing hormone

\section{Introduction}

The plant Vernonia amygdalina (VA) exist as a shrub with petiolate leaf of about $6 \mathrm{~mm}$ diameter and elliptic shape. It grows under a range of ecological zones in Africa and produces large mass of forage and is drought tolerant (Hutchinson and Dalziel, 1963). Its liquid form used as an extract has diverse application in ethno-medicine ranging from treatment of parasitic infections, material (Philipson et al. 1993: Izerbelic et al., 2004), Breast cancer (Wong et al.,2013), Diabetes mellitus (Okolie et al., 2008) and induction of gastric secretion (Owu et al., 2008). In its macerated form it is consumed as vegetables and condiments for soup. In this form it can also serve as the cheapest source of vitamins, minerals and essential amino acid (Okafor, 1983). Phytochemical analysis of the leaves of Vernonia amygdalina yielded two known sesquiterpene lactones: vernolide and vernodalol (Sani et al; 2012). Others include active constituent - essential oil, tannins, alkaloid, saponins, glycosides, anthraquinones and flavonoids all of which may participate in herb-drug interaction. These phytochemicals are believed to be responsible for the myriad medicobiochemical activities of this plant, acting singly or synergistically to produce the result for which Vernonia amygdalina is known including the effective management of diabetes with minimal side effect in clinical experiences.

\section{Material and Method}

Thirty male Wistar rats weighing between 150-200g were divided into 5 groups A, B, C, D, and E. Group A was the normal control that received $0.5 \mathrm{ml}$ dimethylsulphoxide (DMSO) only. Group B served as the diabetic control that was induced $40 \mathrm{mg} / \mathrm{kg}$ b.w of STZ intraperitoneally. Group C received 5i.u/kg body weight of insulin. Group D received $400 \mathrm{mg} / \mathrm{kg}$ b.w of VA and Group E served as the $30 \%$ methanolic VA fraction (flavonoid rich fraction) group receiving $75 \mathrm{mg} / \mathrm{kg}$ b.w of the extract. The animals were treated for 28 days, after which they were sacrificed using chloroform inhalation method. Blood was collected via cardiac puncture from the left ventricle of the heart. Clotted blood was then centrifuged at $300 \mathrm{rpm}$ for 10 minutes to recover serum from clotted cells, serum was separated with sterile syringe and stored frozen for hormonal assay. Luteinizing hormone, follicle-stimulating hormone, and testosterone hormone in the serum were determined using Enzyme-linked immuno-absorbent assay (ELISA) method with Microwell's kit.

\section{Statistical analysis}

Analysis made on the hormones showed data presented as mean \pm standard error of mean. Data were computed and analyzed using one way ANOVA and unpaired Student's ttest. The data were analyzed with the help of a statistical package, SPSS version 18.0 for Windows, considered significant at $\mathrm{p}<0.05$

\section{Results}

Table 1: Hormonal Assay

\begin{tabular}{|c|c|c|c|}
\hline & FSH (ug/L) & LH (ug/L) & $\begin{array}{c}\text { Testosterone } \\
\text { (ug/L) }\end{array}$ \\
\hline Group A (NC) & $2.21 \pm 0.44$ & $1.29 \pm 0.18$ & $1.47 \pm 0.59$ \\
\hline Group B (DC) & $1.20 \pm 0.29^{*}$ & $0.57 \pm 0.07^{*}$ & $0.21 \pm 0.09^{*}$ \\
\hline Group C (INSULIN) & $2.93 \pm 0.10$ & $1.10 \pm 0.34$ & $4.00 \pm 1.99^{\mathrm{a}}$ \\
\hline Group D (Crude) & $2.80 \pm 0.36$ & $1.20 \pm 0.28$ & $4.75 \pm 2.17^{\mathrm{a}}$ \\
\hline $\begin{array}{c}\text { Group E } \\
(30 \% \text { fraction of VA) }\end{array}$ & $1.77 \pm 0.21$ & $1.05 \pm 0.06$ & $2.01 \pm 0.71^{\mathrm{a}}$ \\
\hline
\end{tabular}




\section{International Journal of Science and Research (IJSR) \\ ISSN (Online): 2319-7064}

Index Copernicus Value (2015): 78.96 | Impact Factor (2015): 6.391

Values are expressed as mean \pm SEM, $\mathrm{n}=5$.

*significantly different from $\mathrm{NC}$ at $\mathrm{p}<0.05$;

$\mathrm{a}=$ significantly different from $\mathrm{DC}$ at $\mathrm{p}<0.05$;

From the result as shown in table above (Table 1), it was observed that the concentration of testosterone hormone (TH) was significantly increased $(\mathrm{p}<0.05)$ in group $\mathrm{C}, \mathrm{D}$ and $\mathrm{E}(4.00 \pm 1.99,4.75 \pm 2.17$ and $2.01 \pm 0.71)$ respectively when compared to the diabetic control group $(0.21 \pm 0.09)$ but closely related to the normal control group $(1.47 \pm 0.05)$.
It was also observed that there was no significant increase in serum hormone concentration of Follicule stimulating hormone $(\mathrm{FSH})(2.93 \pm 0.10,2.80 \pm 0.36,1.77 \pm 0.21)$ and Luteinizing hormone (LH) $(1.10 \pm 0.34, \quad 1.20 \pm 0.28$, $1.05 \pm 0.06)$ among and within the treated groups $(\mathrm{C}, \mathrm{D}$ and E) as compared to group A $(2.21 \pm 0.44$ and $1.29 \pm 0.18)$ but a significant increase when compared to group B $(1.20 \pm 0.29$ and $0.57 \pm 0.07$ ) as shown in figure 1 and 2 .

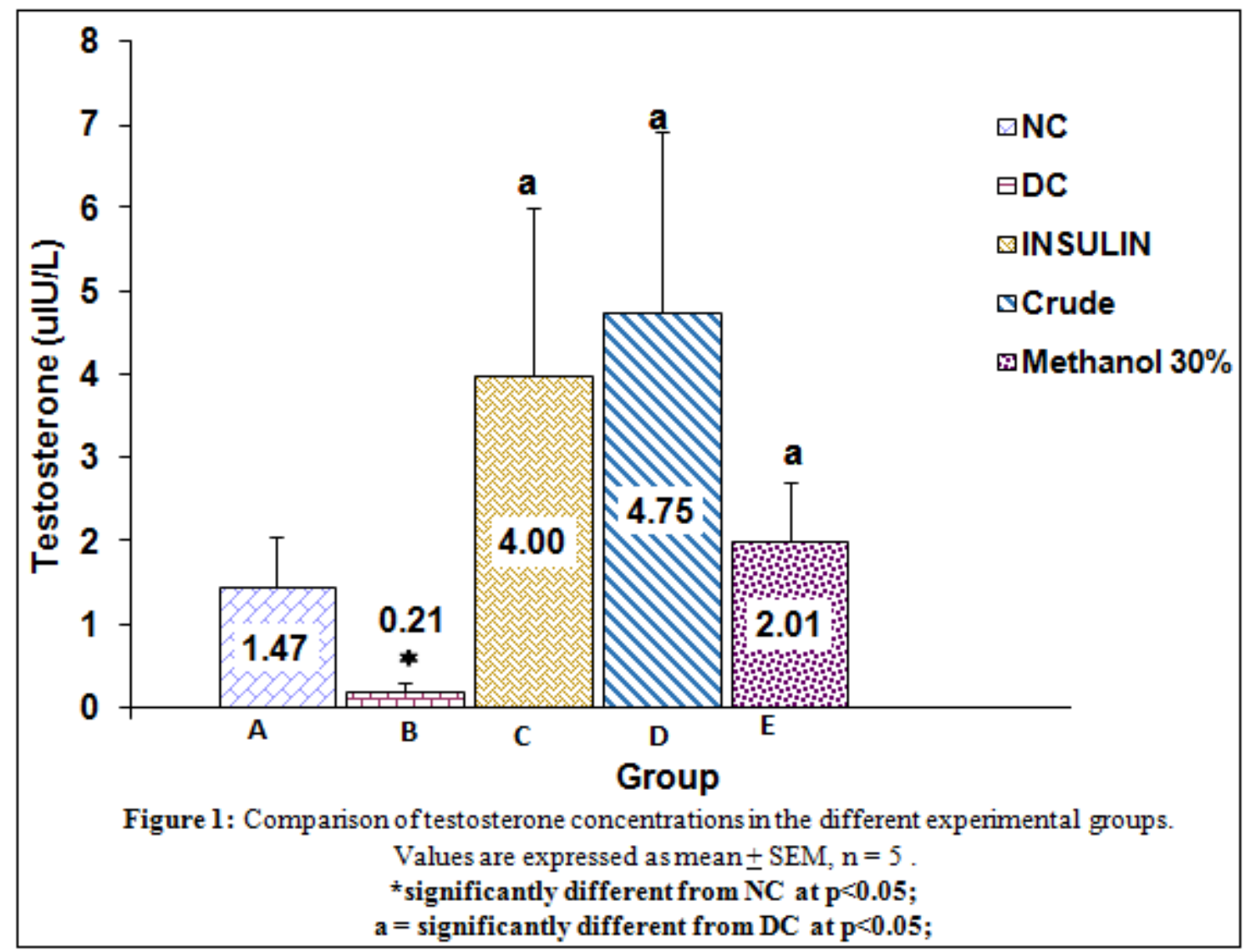

Volume 6 Issue 7, July 2017 www.ijsr.net 

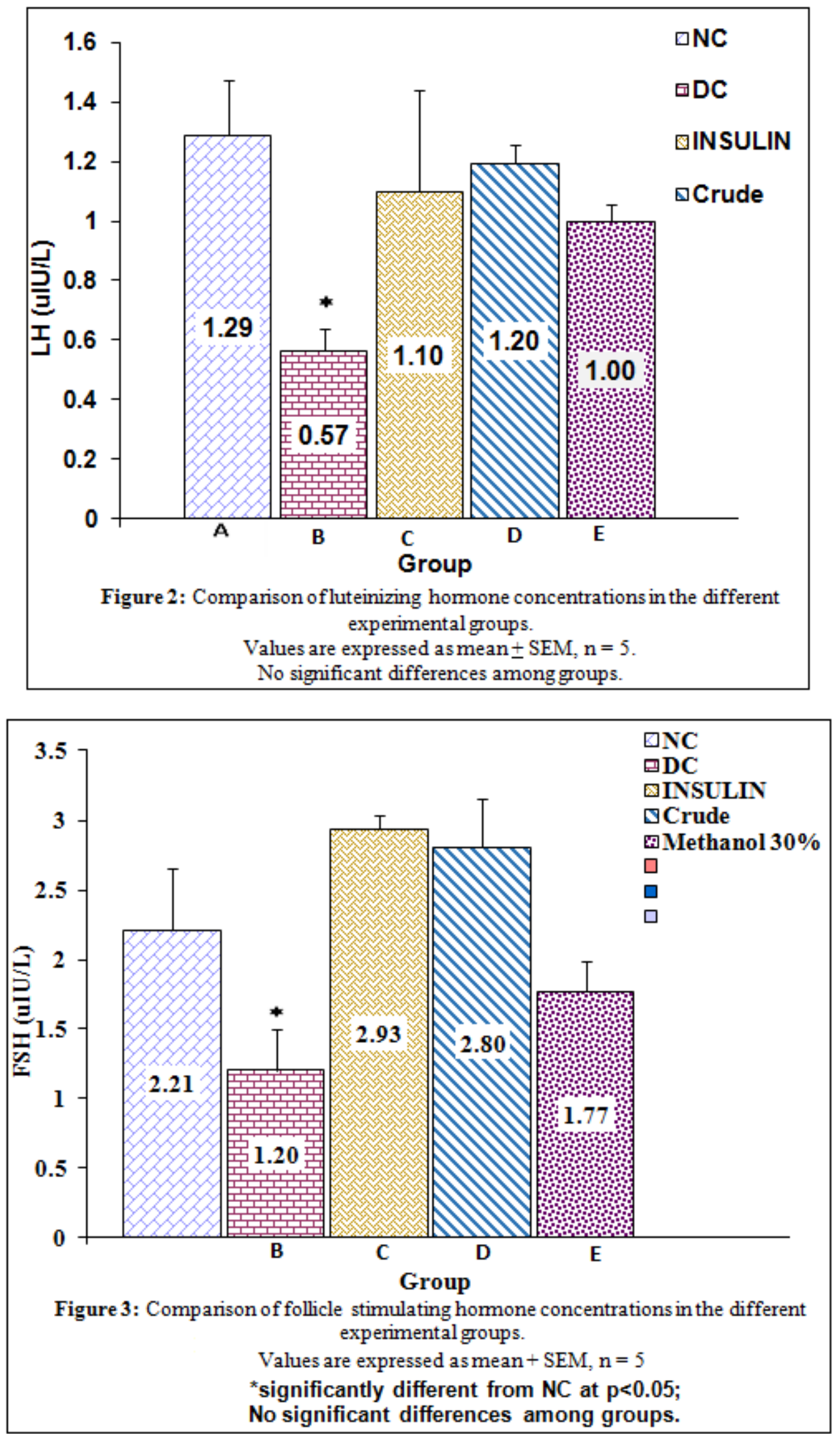

\section{Discussion}

Studies have shown that leaf extract of Vernonia amygdalina has hypoglycemic properties in experimental animals and could be useful in the management of diabetes mellitus (Ong et al., 2011). This study investigated the effect of methanolic leaf extract of Vernonia amygdalina on the serum levels of male reproductive hormones. Testosterone is the major product of the testes and a primary inhibitor of LH secretion in males. FSH levels are the most important endocrine parameters to evaluate testicular function [Bergmann et al.;

Volume 6 Issue 7, July 2017 www.ijsr.net 


\section{International Journal of Science and Research (IJSR) \\ ISSN (Online): 2319-7064}

Index Copernicus Value (2015): 78.96 | Impact Factor (2015): 6.391

1999]. Measurement of FSH and LH show at what stage of the hypothalamic - pituitary - testicular axis a defect is. Increased serum FSH and LH show that the defect is in the hypothalamus or pituitary. LH and FSH both bind to specific receptors on the leydig cells and sertoli cells respectively within the testis. LH affects spermatogenesis indirectly in that, it stimulates androgenous testosterone hormone (TH) production. Testosterone inturn inhibits LH secretion while FSH targets sertoli cells. TH and FSH are hormones that are directed at the seminiferous tubules epithelium. The mechanism of feedback control of FSH is regulated by inhibin a sertoli cell product. Decrease in spermatogenesis is accompanied by decreased production of inhibin and this reduction in negative feedback is associated with reciprocal elevation of FSH levels [Ashiru and Blake, 1979]. A normal level of these hormones is indicative of normal sexual processes in the males.

An interesting observation in this study is the significant increase in serum hormone concentration of testosterone hormone ( $\mathrm{p}<0.05)$ in group C, D and E $(4.00 \pm 1.99,4.75 \pm$ 2.17 and $2.01 \pm 0.71$ respectively) when compared to the diabetic control group $(0.21 \pm 0.09)$ but closely related to the normal control group $(1.47 \pm 0.05)$ concentration of testosterone in group $\mathrm{C}, \mathrm{D}$ and $\mathrm{E}$ when compared to the group A. Also there was no significant increase amongst the treated group (C, D and E) as compared to Group A and B when analysis were made on Luteinizing hormone $1.10 \pm 0.34,1.20 \pm 0.28,1.05 \pm 0.06)$ and Follicle stimulating hormone $(2.93 \pm 0.10,2.80 \pm 0.36,1.77 \pm 0.21)$ among and within the treated groups (C, D and E) as compared to group A $(2.21 \pm 0.44$ and $1.29 \pm 0.18)$ but an increase when compared to group B $(1.20 \pm 0.29$ and $0.57 \pm 0.07)$. This signifies a supplementary role played by insulin, crude extract and $30 \%$ fraction of VA on the anterior pituitary gland to increase testosterone level without a considerable increase in LH and FSH level. These restorative effects so witnessed are ascribed to the bioactive components of the leaf extract of Vernonia amygdalina which are contained in its phytochemical properties. Analysis of mostly the phytochemicals of this species (VA) showed the presence of alkaloids, tannins, saponins and flavonoids with flavonoids as the most preponderant. Flavonoids have been reported to possess antioxidant, anti-allergic, anti-inflammatory, antimicrobial and anticancer activities (Edeoga et al., 2005). The best described property of almost every group of flavonoids amidst other properties is their capacity to act as antioxidant and this is exhibited in its antiatherosclerotic effect as few clinical studies have pointed out that flavonoid intake protect against coronary heart disease (Hertog et al, 1995) which is a major diabetic complication thus improved antioxidants status forms one of the mechanism by which dietary antioxidants contribute to the prevention and reduction of diabetic complications.

\section{Conclusion}

Based on the obtained result, it can be suggested that $30 \%$ methanolic fraction (flavonoid - rich fraction) of VA exhibited an ameliorative effect on the reproductive hormones of STZ induced diabetic male albino Wistar rats

\section{References}

[1] Baris Altay M.D, Sevki Cetinkalp, B Basak, Bulent Semerci M.D (March, 2003). Streptozotocin induced diabetic effects on spermatogenesis with proliferative cell nuclear antigen immunostaining of adult rat testis.

[2] Edeoga, H.O., Okwu, D.E. and Mbaebre, B.O. (2005). Phytochemical constituents of some Nigerian plants. African Journal of Biotechnology 44(7):685-688.

[3] Hertog MG, Kromhout D, Aravanis C, et al. Flavonoid intake and long-term risk of coronary heart disease and cancer in the seven countries study. Arch Intern Med $1995 ; 155: 381-6$.

[4] Izerbelic E.B, Boyant J.L, Walker A (2004). Natural inhibitor of extracellular signal regulated kinases and human breast cancer cells Exp. Biol. and medicine 229 163-169.

[5] Lorke, D. G. (1983). A new approach to practical acute toxicity testing. Archieve of Toxicology. 54. Pp275287.

[6] Ong KW, Hsu A, Song L, Huang D, Tan BK. Polyphenols - rich Vernonia amygdalina shows antidiabetic effects in Streptozotocin-induced diabetic rats. JEthnopharmacol. 2011 Jan 27; 133(2): 598 - 607.

[7] Okolie, U.V; Okeke, C E; J M, Ehiemere; 10 (2008). Hypoglycaemic indices of Vernonia amygdalina on postprandial Blood glucose concentrations of healthy humans. Afri. J. Biotech 7:4581-4585.

[8] Owu, D U, Ben E .E, Antai, A .B, Ekpe E.A, Udia P. (2008). Stimulating of gastric acid secretion and intestinal motility by Vernonia amygdalina extract. Fitoterapia. 79:92-100.

[9] Phillipson J.D, Wright C.W, kioby G.C, Warhurst D.C (1993) phytochemistry of some plants used in traditional medicine for the treatment of protozoal diseases Abstracts. Int. symposium of the phytochemical society of Europe; University of Lausame, Switzerland, P.L3

[10] Trease, G.E and Evans, W.C (1996), Trease and Evans pharmacognosy $14^{\text {th }}$ edition w.b Ssuvnder company limited, London Pp191-293. 